\title{
Электронные свойства пленок силицена, подвергнутых нейтронному легированию
}

\author{
(C) А.Е. Галашев ${ }^{1,2}$, А.С. Воробьев ${ }^{1}$ \\ ${ }^{1}$ Институт высокотемпературной электрохимии Уральского отделения Российской академии наук, \\ 620990 Екатеринбург, Россия \\ ${ }^{2}$ Уральский федеральный университет им. первого президента России Б.Н. Ельцина, \\ 620002 Екатеринбург, Россия \\ E-mail: galashev@ ihte.uran.ru
}

Поступила в Редакцию 2 сентября 2019 г.

В окончательной редакции 28 января 2020 г.

Принята к публикации 29 января 2020 г.

Радиационное легирование фосфором монокристаллического кремния сохраняет структуру образца, снижает внутренние напряжения, повышает время жизни неосновных носителей заряда. Настоящая работа посвящена исследованию влияния добавок фосфора на электронные свойства силицена. Квантовомеханическим методом рассчитаны спектры плотности электронных состояний легированного фосфором однослойного и двухслойного силицена $2 \times 2$ на графитовой подложке. Присутствие углеродной подложки придает силицену проводниковые свойства вследствие $p$-p-гибридизации. Легирование фосфором может сохранить или изменить приобретенные силиценом металлические свойства. Местоположение легирующих атомов фосфора в силицене влияет на прохождение перехода полупроводник-проводник. Теоретическая удельная емкость легированного фосфором силиценового электрода снижается, и он становится менее эффективным для применения в литий-ионных батареях. Однако увеличение проводимости этого материала способствует его использованию в качестве солнечных элементов.

Ключевые слова: графит, силицен, фосфор, электронные состояния.

DOI: $10.21883 /$ FTP.2020.06.49392.9252

\section{1. Ведение}

Разработка технологии изготовления тонких кремниевых пленок позволила производить и снизила стоимость тонкопленочных транзисторов и гибких солнечных элементов [1]. Тонкие пленки кремния получают несколькими способами, такими как электроосаждение из расплавленных солей на металлическую или стеклоуглеродную подложку [2,3], газофазное химическое осаждение с различными способами активации прекурсоров [4] и плазменный эпитаксиальный рост на кремниевых пластинах [5]. Самой тонкой кремниевой пленкой является силицен - двумерный материал с запрещенной зоной $(33) \sim 27$ мэВ. Силицен уже получают на $\operatorname{Ag}(111)$ [6,7], $\mathrm{ZrB}_{2}(0001)$ [8] и $\operatorname{Ir}(111)$ [9] подложках. В работе [10] было продемонстрировано осаждение силицена на графите. Силицен, как и тонкие пленки кремния, предлагается использовать в солнечных элементах [11], микроэлектронике [12] и в литийионных батареях [13]. Свойства силицена изучались как с помощью квантово-механического моделирования [14], так и методом классической молекулярной динамики $[15,16]$. Для увеличения долговечности солнечных элементов и приобретения $n$-проводимости $[17,18]$ тонкие пленки кремния подвергаются нейтронному легированию [19], в ходе которого происходит частичное превращение кремния в фосфор, согласно реакции

$$
\mathrm{Si}^{30}+n \rightarrow \mathrm{Si}^{31}(2.62 \mathrm{~h}) \rightarrow \mathrm{P}^{31}+\beta^{-},
$$

где введены обозначения: $n-$ нейтрон, $\mathrm{h}-$ час, а $\beta^{-}-$ бета-излучение.

Нейтронное легирование полупроводников выполняется для улучшения их электрических свойств. Если ядро поглощает нейтрон, то полученное составное ядро может находиться в нестабильном состоянии до тех пор, пока не станет стабильным. При этом возможно изменение атомного номера элемента вследствие ядерной трансмутации. Облучение $\mathrm{Si}$ тепловыми нейтронами приводит только к одной ядерной реакции с коротким периодом полураспада ${ }^{31} \mathrm{Si}$ (составляющим 2.62 ч).

Атом ${ }^{31} \mathrm{P}$ имеет пять электронов во внешней оболочке. Поэтому в результате такого нейтронного трансмутационного допирования (НТД) создается легирование примесью $n$-типа. Для легирования кремния, имеющего высокое удельное сопротивление, НТД метод является самым точным и единым способом введения фосфора. Здесь ключевым параметром является удельное сопротивление, которое отражает концентрацию носителей заряда. С помощью облучения достигается однородность легирования. При этом флюенс (интеграл по времени от плотности потока нейтронов или энергии) определяет степень легирования. Вырожденные или очень высоко легированные полупроводники имеют уровни проводимости, сравнимые с соответствующими уровнями металлов. Подобно металлам, в вырожденных 
полупроводниках занятые и незанятые энергетические уровни больше не разделены запрещенной зоной. Вырожденные полупроводники часто используются в современных интегрированных схемах в качестве замены металла. Идентичные образцы, полученные методом НТД, характеризуются низким изменением удельного сопротивления. Это достигается путем точного контроля дозы облучения, выдержки образцов после облучения и, если необходимо, проведения отжига для устранения вызванных облучением дефектов.

Концентрация фосфора $\left(\mathrm{cm}^{-3}\right)$ в кремнии с легированием $n$-типа определяется как

$$
[P]=1 /(\rho e \mu)
$$

где $\rho-$ удельное электрическое сопротивление $(\mathrm{OM} \cdot \mathrm{cm}), e-$ заряд электрона, $\mu-$ дрейфовая подвижность электронов в кристаллической решетке кремния. Легирование должно выполняться при точном контроле потока нейтронов. Желательно, чтобы тепловые нейтроны доминировали в спектре облучения, чтобы уменьшить радиационные повреждения в кристаллической решетке быстрыми нейтронами.

Цель данной работы - исследовать электронные свойства силицена на углеродной подложке после нейтронного легирования, т. е. превращения от 6.25 до 25\% атомов кремния в фосфор.

\section{2. Описание модели}

Расчеты электронных свойств модифицированного силицена проводились с использованием программного пакета Siesta [20]. В данной работе мы рассматриваем последствие нейтронного облучения силицена на углеродной подложке. В ходе такого облучения в силицене происходит превращение некоторых атомов кремния в атомы фосфора. Силицен представлялся двумя способами: однослойным - как сверхъячейка $2 \times 2$ (восемь атомов кремния, находящихся в двух ху плоскостях) и двухслойным - две сверхъячейки силицена $2 \times 2$ (шестнадцать атомов кремния в четырех $x y$ плоскостях). Расчеты выполнялись как для свободностоящего силицена, так и для силицена на углеродной подложке. Толщина углеродной подложки подбиралась с помощью проведения дополнительного компьютерного моделирования. Рассматривались подложки, состоящие от одного до четырех графитовых слоев. Один слой подложки задавался 18 атомами углерода, т. е. сверхъячейкой $3 \times 3$. Геометрической оптимизации были подвергнуты все атомы системы „силицен-углеродная подложка“. Однако переход от объемного слоистого материала к двумерной структуре, состоящей всего из нескольких слоев, сопровождается сокращением межслоевого расстояния. Поэтому, когда число графитовых слоев в модели было больше одного, осуществлялось вертикальное закрепление атомов $C$ в каждом из слоев. Этот прием позволяет сохранить расстояние между слоями подложки равным экспериментально установленному значению 0.3314 нм в графите.

В расчетах использовались периодические граничные условия Борна-Кармана, реализованные в программе Siesta. Параметры трансляции для используемых графеновой и силиценовой сверхъячеек равны 0.741 и 0.774 нм соответственно. Параметр трансляции в направлениях $x$ и $y$ для объединенной силицен-графитовой сверхячейки выбран равным 0.7575 , т. е. соответствовал аналогичной величине, используемой в работе [21], где показано сохранение электронных свойств как свободностоящего силицена, так и графена в объединенной сверхъячейке. Вектор трансляции в направлении $z$ был выбран равным $35 \AA$. Таким образом, используемая система представляла собой бесконечно транслируемую короткопериодную сверхрешетку. Подобные сверхрешетки часто используются при моделировании двумерных систем. Например, сверхъячейка графена $3 \times 3$ применялась для определения энергии адсорбции алюминия и серебpa [22], а также при исследовании хранения водорода на графене с адсорбированным палладием [23]. Сверхъячейка силицена $2 \times 2$ служила базовым элементом для определения предела литиирования силицена [24], а также для установления возможности хранения водорода на металл-функционализированном силицене [25].

Легирование проводилось путем замены атомов кремния атомами фосфора. При исследовании моно- и бислоя силицена на графитовой подложке замене, отражающей нейтронное легирование, подвергалось от 1 до 2 атомов кремния. Такое замещение выполнялось по всем возможным местоположениям атомов в силицене, включая его верхнюю и нижнюю подрешетки. Затем все рассчитываемые характеристики усреднялись по наборам рассматриваемых конфигураций. Были построены парциальные спектры электронных состояний (PDOS). Системы были подвергнуты геометрической оптимизации с использованием обобщенного градиентного приближения в форме РВЕ. Динамическую релаксацию атомов проводили до тех пор, пока изменение полной энергии системы не становилось меньше 0.001 эВ. Энергию обрезания базиса плоских волн полагали равной 200 Ry. Зона Бриллюэна задавалась методом Монхорста-Пака с использованием $10 \times 10 \times 1 k$-точек. Исследование основывалось на двухэкспоненциальном поляризационном базисном наборе (DZP).

Энергия адгезии между графитовой подложкой и листом совершенного силицена рассчитывалась согласно

$$
E_{\mathrm{ad}}=\frac{-\left(E_{\mathrm{tot}}-E_{\mathrm{Si}(\mathrm{P})}-E_{\mathrm{C}}\right)}{n_{\mathrm{cell}}}
$$

где $E_{\text {tot }}-$ полная энергия всей системы, $E_{\mathrm{Si}(\mathrm{P})}-$ полная энергия силицена (не подвергнутого облучению или легированного фосфором), $E_{\mathrm{C}}-$ полная энергия углеродной подложки, $n_{\text {cell }}-$ количество элементарных ячеек в сверхъячейке силицена. При этом атомы фосфора в системе рассматривались как принадлежащие силиценовой сверхъячейке. 


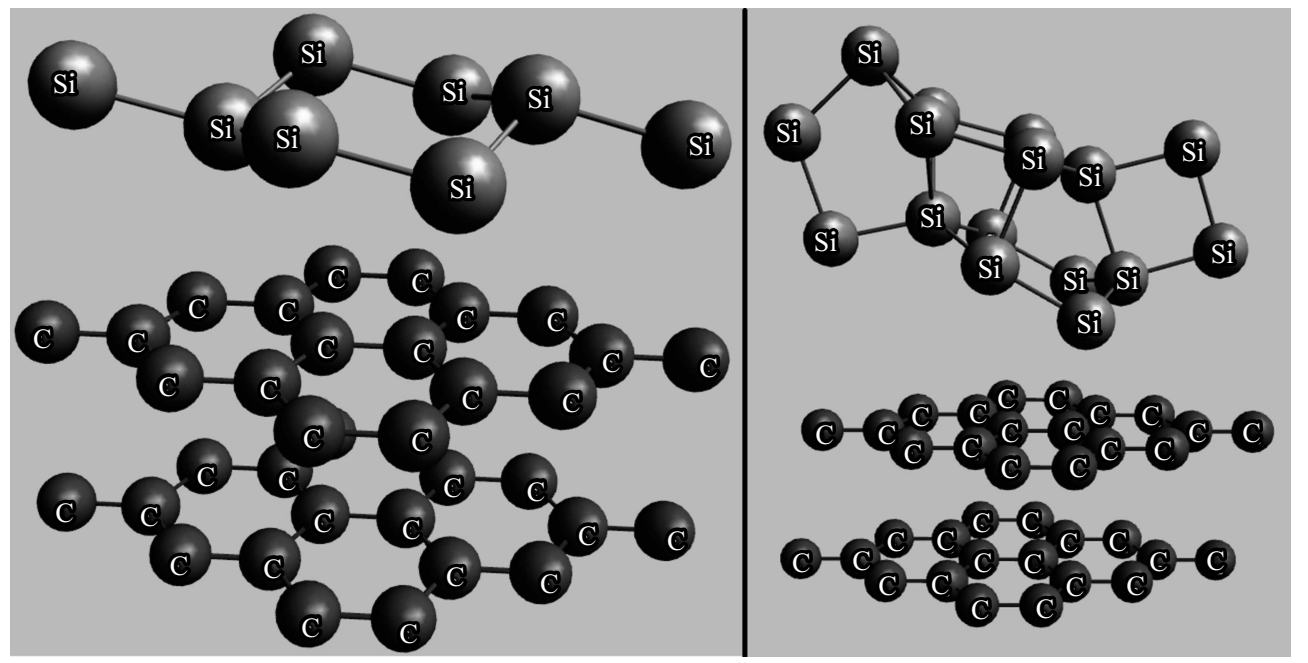

Рис. 1. Конфигурации систем $\mathrm{Si}-\mathrm{C}$ после геометрической оптимизации: слева - однослойный, справа - двухслойный силицен. Графитовая подложка представлена двумя слоями.

Общим выражением для энергии связи в силицене в рассматриваемых здесь системах является

$$
E_{\mathrm{bond}}=\frac{-\left(E_{\mathrm{tot}}-n_{\mathrm{Si}} E_{\mathrm{Si}}-n_{\mathrm{P}} E_{\mathrm{P}}-E_{\mathrm{C}}\right)}{n},
$$

где $E_{\mathrm{Si}}, E_{\mathrm{P}}$ - полные энергии, рассчитанные для одного атома кремния и фосфора соответственно, $n_{\mathrm{Si}}$ и $n_{\mathrm{P}}-$ количество атомов $\mathrm{Si}$ и $\mathrm{P}$ в системе, $n=n_{\mathrm{Si}}+n_{\mathrm{P}}+n_{\mathrm{C}}-$ количество всех атомов в системе.

Теоретическая удельная емкость модифицированного листа силицена, выполняющего роль электрода в химическом источнике тока, была рассчитана по формуле

$$
C_{T S}=\frac{x \mathrm{~F}}{M}
$$

где $x$ - количество взаимодействующих электронов, F - число Фарадея, $M$ - молярная масса элементов в системе.

\section{3. Результаты и обсуждение}

Мы выполнили расчеты физических свойств как автономного (без подложки) одно- и двухслойного силицена $(\mathrm{Si})$, так и силицена на графитовой подложке $(\mathrm{Si}-\mathrm{C})$. Для определения оптимального количества слоев подложки были использованы 4 системы, содержащие от 1 до 4 слоев графена, в которых содержалось от 18 до 72 атомов углерода. После геометрической оптимизации данных систем были рассчитаны энергии адгезии, характеризующие сцепление между силиценом и углеродной подложкой. В табл. 1 представлены значения энергии адгезии в зависимости от количества слоев в графитовой подложке. Видно, что увеличение толщины подложки с двух слоев до трех изменяет энергию адгезии между подложкой и силиценом на $\sim 1.5 \%$ как в случае однослойного, так и двухслойного силицена.
Таблица 1. Энергия адгезии между силиценом и графитовой подложкой, при наличии в силицене от 1 до 2 листов, а в подложке от 1 до 4 слоев, эВ/эл.яч.

\begin{tabular}{c|c|c|c|c}
\hline \multirow{2}{*}{$\begin{array}{c}\text { Количество } \\
\text { листов силицена }\end{array}$} & \multicolumn{4}{|c}{ Количество слоев графитовой подложки } \\
\cline { 2 - 5 } & 1 & 2 & 3 & 4 \\
\hline 1 & 0.122 & 0.131 & 0.133 & 0.132 \\
2 & 0.124 & 0.092 & 0.094 & 0.091
\end{tabular}

Учет четырех слоев подложки приводит к отличию в $E_{\mathrm{ad}}$ от варианта с двумя слоями не более чем на $1.1 \%$ в обоих случаях. Поэтому в дальнейших расчетах использовалась графитовая подложка, представленная двумя слоями, содержащими 36 атомов углерода.

На рис. 1 показаны $\mathrm{Si}-\mathrm{C}$ системы после геометрической оптимизации. В ходе оптимизации произошли заметные геометрические перестроения по отношению к свободностоящему, не модифицированному силицену. Так, среднее расстояние между подрешетками силицена $\mathrm{Si}-\mathrm{Si}_{\text {int }}$ увеличилось с 0.44 до $0.56 \AA$ и с 0.44 до $1.01 \AA$ для однослойного и двухслойного силицена соответственно.

Парциальные спектры плотности состояний как автономного одно- и двухслойного силицена, так и силицена на углеродной подложке представлены на рис. 2. Однослойный силицен является полупроводником с шириной запрещенной зоны 0.027 эВ. Его размещение на графитовой подложке ведет к возникновению проводниковых свойств. Проявление электронной проводимости в однослойном силицене является следствием его взаимодействия с подложкой. Как видно из рис. 2, проводимость возникает вследствие взаимодействия $2 p$-электронов углерода с $3 p$-электронами силицена, что согласуется с данными работ [26,27]. Наши расчеты показывают, что двухслойный силицен является проводником вследствие 

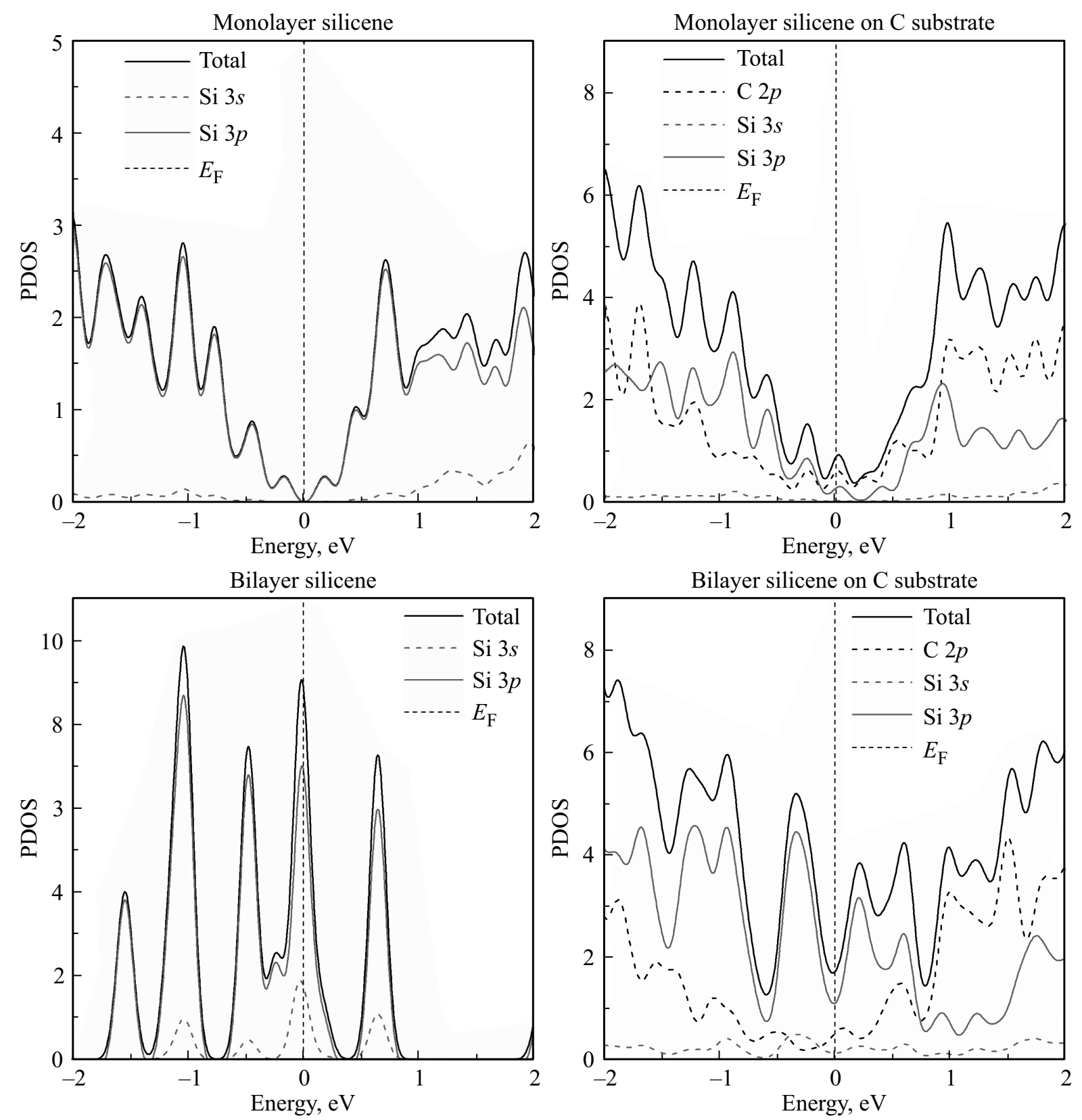

Рис. 2. Парциальные спектры плотности состояний однослойного и двухслойного силицена: слева - автономный силицен, справа - силицен на графитовой подложке.

взаимодействия $p$ - и $s$-электронов его различных слоев. Появление металлической проводимости в двухслойном силицене также было показано в работе [28].

Число атомов кремния, замещенных фосфором, изменялось от 1 до 2 во всех рассмотренных случаях. В табл. 2 представлены рассчитанные характеристики, такие как: среднее расстояния между подрешетками силицена $\left(\mathrm{Si}-\mathrm{Si}_{\mathrm{int}}\right)$; среднее расстояние между листами силицена $\left(\Delta_{\mathrm{Si}}\right)$; средние длины связи между атомами кремния ( $\left.\mathrm{Si}-\mathrm{Si}_{\text {bond }}\right)$ и атомами кремния и фосфора $(\mathrm{Si}-\mathrm{P})$; энергия адсорбции между силиценом, модифицированным фосфором, и углеродной подложкой $\left(E_{\mathrm{ad}}\right)$; энергия связи в модифицированным фосфором силицене
$\left(E_{\mathrm{bond}}\right)$; теоретическая удельная емкость рассматриваемых систем $\left(C_{T S}\right)$, а также ширина запрещенной зоны. При увеличении количества замещенных фосфором атомов кремния в силицене происходит увеличение расстояния между подрешетками $\mathrm{Si}-\mathrm{Si}_{\text {int }}$ с 0.44 до $0.66 \AA$. Для силицена на графитовой подложке длины $\mathrm{Si}-\mathrm{Si}_{\text {bond }}$ и $\mathrm{Si}-\mathrm{P}$ соответствуют аналогичным характеристикам автономного силицена, т. е. $\approx 2.31 \AA$.

Межплоскостное расстояние между углеродной подложкой и нижней подрешеткой силицена $\mathrm{Si}-\mathrm{C}_{\text {int }}$ во всех рассмотренных случаях составило $\sim 3.44 \AA$. Также не зависящими от количества атомов фосфора оказались средние длины связи $\mathrm{Si}-\mathrm{C}_{\text {bond }}$ и $\mathrm{C}-\mathrm{C}$, равные 3.64 

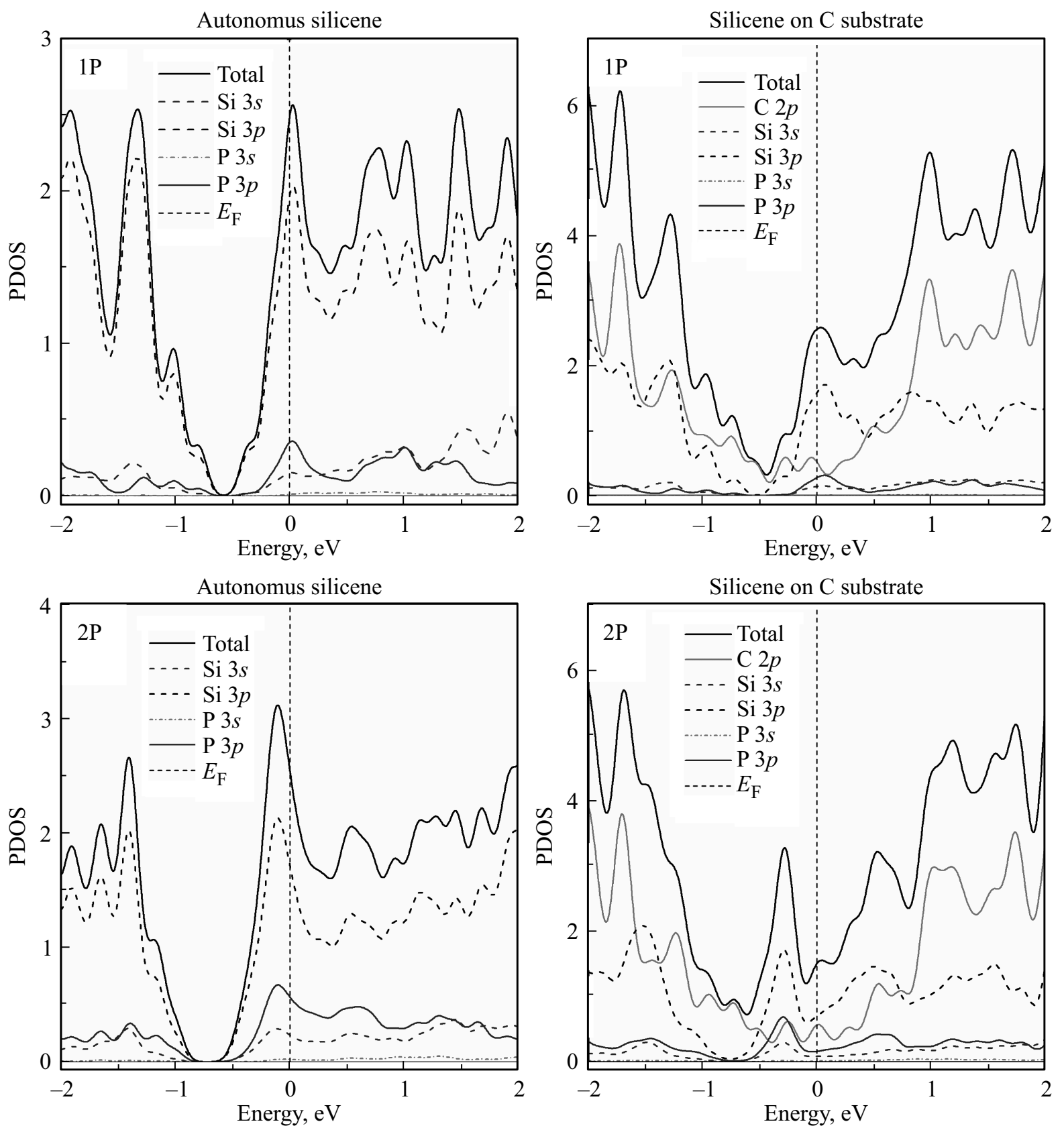

Рис. 3. Парциальные спектры электронных состояний силицена при замещении от 1 до 2 атомов кремния атомами фосфора: слева - однослойный автономный модифицированный силицен, справа - такой же силицен на графитовой подложке.

и $1.44 \AA$ соответственно. Расстояние между атомами кремния $\left(\mathrm{Si}-\mathrm{Si}_{\mathrm{bond}}\right)$ в модифицированном фосфором автономном листе силицена и в соответствующем слое силицена на углеродной подложке близки к $2.31 \AA$. Однако в двухслойном силицене в обоих случаях длина связи $\mathrm{Si}-\mathrm{Si}$ увеличивается до $2.38 \AA \AA$. Рост длин связи $\mathrm{Si}-\mathrm{Si}_{\text {bond }}$ вызван увеличением расстояния между подрешетками силицена. В присутствии графитовой подложки расстояние между листами как немодифицированного, так и модифицированного двухслойного силицена $\Delta_{\mathrm{Si}}$ увеличивается на $\sim 5 \%$. При этом не было обнаружено зависимости $\Delta_{\mathrm{Si}}$ от количества атомов фосфора в сили- цене. Подложка и число атомов $\mathrm{P}$ оказывают неоднозначное влияние на длину $\mathrm{Si}-\mathrm{P}-$ связи. Наименьшее значение $\mathrm{Si}-\mathrm{P}$-связи $(2.28 \AA)$ получено для однослойного силицена на подложке. Эта величина близка к длине $\mathrm{Si}-\mathrm{P}$-связи (2.24 А), полученной с помощью $a b$ initio исследования химической функционализации силицена фосфором [29]. Длины связи $\mathrm{Si}-\mathrm{Si}_{\text {bond }}$ на $1-2 \%$ выше длин связи $\mathrm{Si}-\mathrm{P}$. Полученные длины связи $\mathrm{Si}-\mathrm{Si}_{\text {bond }}$ и $\mathrm{Si}-\mathrm{P}$ согласуются с данными работ $[30,31]$.

Замена кремния фосфором также влияет на энергетические характеристики системы (табл. 2). Относительная энергия связей $E_{\mathrm{bond}}$ в однослойном и двухслойном 

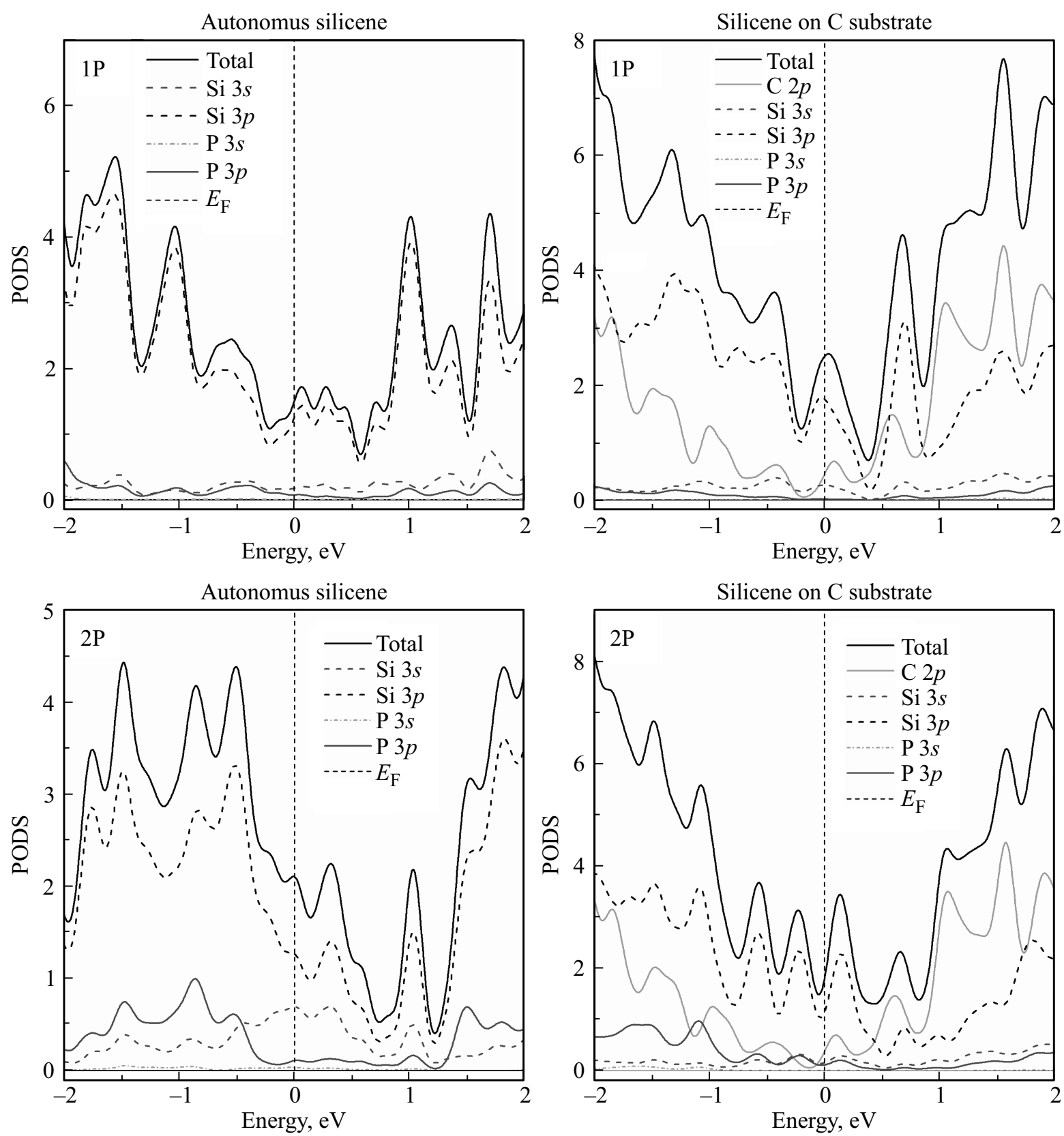

Рис. 4. Парциальные спектры электронных состояний двухслойного силицена при замещении от 1 до 2 атомов кремния атомами фосфора: слева - автономный силицен, справа — аналогичный двухслойный силицен на графитовой подложке.

свободностоящем силицене при наличии в них одного атома фосфора равна 4.72 и 4.94 эВ соответственно. При замене еще одного атома кремния на атом фосфора энергия связей в однослойном силицене не изменяется, в то время как энергия связи в двухслойном силицене увеличивается до 4.95 эВ. В присутствии углеродной подложки энергия связи увеличивается как в однослойном, так и двухслойном силицене в независимости от того, сколько атомов $\mathrm{Si}$ замещено на атомы $\mathrm{P}$.

Энергия адгезии между однослойным силиценом, допированным одним атомом Р, и графитовой подложкой на $\sim 35 \%$ выше, чем между двухслойным силиценом такого же состава и той же подложкой. В целом подоб- ная ситуация сохраняется после допирования силицена двумя атомами Р, где различие между энергиями адгезии в первом и втором случаях составило $33 \%$. Буква М в строке „запрещенная зона (33)“ табл. 2 означает „металл“, а цифры в этой строке указывают величину (в эВ) запрещенной зоны, которая может появиться в какой-либо из конфигураций.

Возможность использования данных нанокомпозитов в солнечной энергетике и в качестве анода литийионных аккумуляторов проверяется на основе наличия высокой удельной емкости $C_{T S}$. Для оценки гравиметрической емкости были использованы следующие соотношения максимального литиирования мате- 
Таблица 2. Геометрические и энергетические характеристики модифицированного одно- и двухслойного силицена без углеродной подложки и при ее наличии

\begin{tabular}{|c|c|c|c|c|c|c|c|c|}
\hline \multirow{3}{*}{ Свойство } & \multicolumn{4}{|c|}{ Без подложки } & \multicolumn{4}{|c|}{ Графитовая подложка } \\
\hline & \multicolumn{2}{|c|}{1 слой $\mathrm{Si}$} & \multicolumn{2}{|c|}{2 слоя $\mathrm{Si}$} & \multicolumn{2}{|c|}{1 слой $\mathrm{Si}$} & \multicolumn{2}{|c|}{2 слоя $\mathrm{Si}$} \\
\hline & $1 \mathrm{P}$ & $2 \mathrm{P}$ & $1 \mathrm{P}$ & $2 \mathrm{P}$ & $1 \mathrm{P}$ & $2 \mathrm{P}$ & $1 \mathrm{P}$ & $2 \mathrm{P}$ \\
\hline $\mathrm{Si}-\mathrm{Si}_{\text {int }}, \AA$ & 0.60 & 0.66 & 0.75 & 0.76 & 0.66 & 0.72 & 1.05 & 1.04 \\
\hline$\Delta_{\mathrm{Si}}, \AA$ & - & - & 1.96 & 1.98 & - & - & 2.07 & 2.06 \\
\hline $\mathrm{Si}-\mathrm{Si}_{\text {bond }}, \AA$ & 2.33 & 2.29 & 2.36 & 2.38 & 2.29 & 2.31 & 2.38 & 2.38 \\
\hline $\mathrm{Si}-\mathrm{P}, \AA$ & 2.32 & 2.27 & 2.32 & 2.35 & 2.28 & 2.32 & 2.36 & 2.35 \\
\hline$E_{\mathrm{ad}}$, эВ/эл.яч. & - & - & - & - & 0.130 & 0.128 & 0.085 & 0.086 \\
\hline$E_{\text {bond }}$, эB & 4.72 & 4.72 & 4.94 & 4.95 & 4.815 & 4.836 & 5.020 & 5.051 \\
\hline$C_{T S}, \mathrm{MAч/ \Gamma}$ & 3980.7 & 3768.0 & 4089.1 & 3980.7 & 1616.3 & 1552.7 & 2272.2 & 2222.6 \\
\hline 33, эВ & M & M & M & $\mathrm{M} / 0.236$ & M & M & M & M/0.018/0.009 \\
\hline
\end{tabular}

риалов, составляющих электрод: $\mathrm{SiLi}_{4.4}$ [32], $\mathrm{PLi}_{3}$ [33], $\mathrm{C}_{6} \mathrm{Li}$ [34]. Аноды на основе $\mathrm{Si}$ имеют теоретическую емкость $C_{T S}=4200 \mathrm{MA} \cdot$ ч $\cdot \Gamma^{-1}$, которую также можно отнести к свободностоящему одно- и двухслойному силицену. На графитовой подложке предельная емкость совершенного силицена снижается: для однослойного

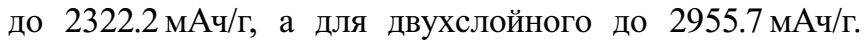
Следует отметить, что при частичной замене кремния фосфором теоретическая удельная емкость $C_{T S}$ уменьшается из-за большей массы фосфора и снижения теоретического максимального количества электронов, участвующих в реакции с литием (c 4.4 электронов у кремния до 3 у фосфора). Таким образом, $C_{T S}$, рассчитанная для свободностоящего модифицированного листа силицена, выше соответствующей величины для системы „модифицированный силицен-углеродная подложка“.

Допирование однослойного силицена фосфором, так же как его нахождение на графитовой подложке, приводит к металлизации системы. Примеры парциальных спектров электронных состояний модифицированного фосфором свободностоящего листа силицена и соответствующего однослойного силицена на углеродной подложке показаны на рис. 3. Введение атомов фосфора в силицен способствует появлению проводимости, так как фосфор является элементом с 5 внешними электронами, в то время как кремний имеет всего 4 таких электрона. Другими словами, встраивание атома фосфора в структуру силицена должно давать один свободный электрон. Уже при введении одного атома фосфора в лист силицена энергетическая щель между валентной зоной и зоной проводимости исчезает, и силицен приобретает проводниковые свойства вследствие $p-p$-гибридизации, что согласуется с данными работы [29]. Дальнейшее увеличение количества замещенных атомов кремния до 2 не изменяет проводниковые свойства системы (рис. 4).

На рис. 4 представлены парциальные спектры наиболее вероятных электронных состояний модифицированного фосфором двухслойного силицена. Как автономный двухслойный силицен, так и соответствующий силицен на углеродной подложке, как правило, сохраняют свои
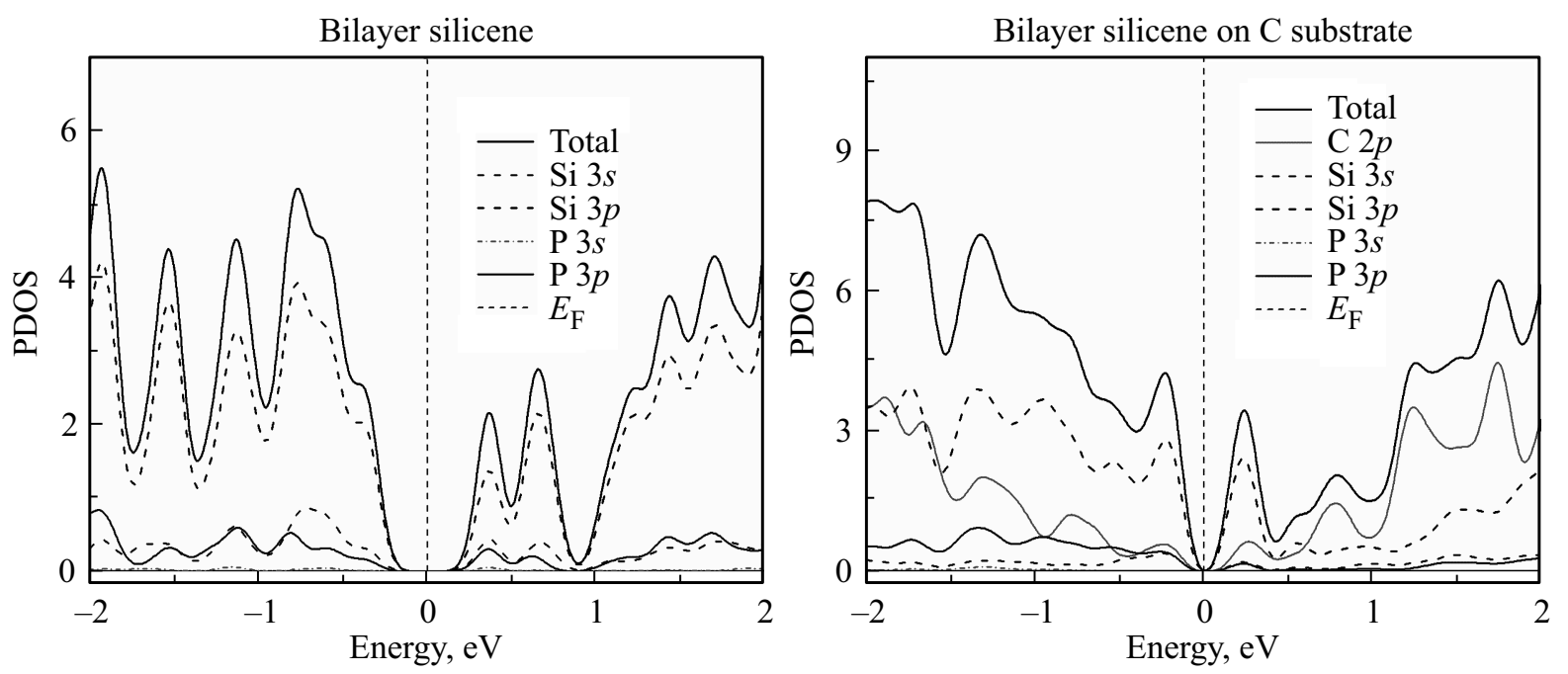

Рис. 5. Парциальные спектры электронных состояний двухслойного силицена после замены атома кремния на атом фосфора в нижней подрешетке каждого из листов силицена: слева - автономный силицен, справа - силицен на графитовой подложке. 
проводниковые свойства. Однако, в частном случае, когда атомы $\mathrm{Si}$, замещаемые на атомы $\mathrm{P}$, находятся в нижней подрешетке как верхнего, так и нижнего листа силицена, система после допирования может приобретать полупроводниковые свойства.

Спектры электронных состояний одного из таких вариантов допирования (атомы $\mathrm{P}$ находятся в нижних подрешетках верхнего и нижнего листов силицена) показаны на рис. 5. Видно, что для автономного силицена в данном случае происходит переход к полупроводниковому состоянию с шириной запрещенной зоны 0.236 эВ. При наличии графитовой подложки для двухслойного силицена данной конфигурации происходит сужение ширины запрещенной зоны до 0.018 эВ. Аналогичный переход в состояние полупроводника наблюдался при замещении двух атомов кремния атомами фосфора в нижней подрешетке нижнего листа силицена. В этом случае автономный двухслойный силицен металлизируется, в то время как силицен на углеродной подложке приобретает полупроводниковые свойства с шириной запрещенной зоны $\sim 0.009$ эВ.

\section{4. Заключение}

Полученные результаты показывают, что при содержании от 6 до 25\% фосфора в свободностоящем модифицированном одно- и двухслойном силицене происходит металлизация системы вследствие взаимодействия $3 p$-электронов кремния с $3 p$-электронами фосфора. Последовательное повышение содержания фосфора в силицене вызывает постепенное увеличение расстояния между подрешетками силицена. Замещение атомов кремния атомами фосфора в системе „силицен-графитовая подложка“ приводит к увеличению стабильности системы, связанной с геометрическими перестроениями в листе силицена. В двухслойном силицене длина связи $\mathrm{Si}-\mathrm{Si}$ на 3\% больше по сравнению с однослойным листом силицена. Удлинение связи коррелируют с увеличением расстояния между подрешетками силицена. Сокращение длин связи $\mathrm{Si}-\mathrm{P}$ на $1-2 \%$ по сравнению с $\mathrm{Si}-\mathrm{Si}-$ связями не приводит к существенной перестройке кристаллической структуры силицена.

В результате $p-p$-гибридизации система „силиценуглеродная подложка“ в большинстве случаев приобретает проводниковые свойства. Однако присутствие двух замещающих $\mathrm{P}$ атомов в двухслойном силицене делает возможным переход проводник-полупроводник. Данный переход связан с определенным положением данных атомов в двухслойном силицене.

Таким образом, для улучшения полупроводниковых свойств силицена на углеродной подложке необходимо не только правильно подобрать флюенс нейтронного облучения, влияющего на количество превращений $\mathrm{Si}$ в P, но также знать энергию нейтронов, чтобы контролировать дефектообразование и геометрические параметры нанокомпозита. Контроль за легированием фосфором должен приводить к получению конечного продукта с заданным однородным электросопротивлением, что достигается при достаточно однородной структуре модифицированного силицена.

\section{Финансирование работы}

Исследование выполнено при финансовой поддержке гранта Российского научного фонда (проект № 16-1300061).

\section{Конфликт интересов}

Авторы заявляют, что у них нет конфликта интересов.

\section{Список литературы}

[1] A.G. Aberle. Thin Sol. Films, 517 (17), 4706 (2009).

[2] A.V. Isakov, A.P. Apisarov, A.O. Khudorozhkova, M.V. Laptev, Yu.P. Zaikov. IOP Conf. Series: J. Physics: Conf. Series, 1134, 012021 (2018).

[3] S.I. Zhuk, L.M. Minchenko, O.V. Chemezov, V.B. Malkov, O.V. Grishenkova, V.A. Isaev, Yu.P. Zaikov, Sh. Qi. Adv. Mater. Res., 1088, 429 (2015).

[4] M.N. Andreev, A.K. Rebrov, A.I. Safonov, N.I. Timoshenko, K.V. Kubrak, V.S. Sulyaeva. J. Engin. Phys. Thermophys., 88 (4), 1003 (2015).

[5] M. Moreno, P. Roca i Cabarrocas. EPJ Photovolt., 1, 10301 (2010).

[6] P. Vogt, P. De Padova, C. Quaresima, J. Avila, E. Frantzeskakis, M.C. Asensio, A. Resta, B. Ealet, G.L. Lay. Phys. Rev. Lett., 108, 155501 (2012).

[7] D. Chiappe, C. Grazianetti, G. Tallarida, M. Fanciulli, A. Molle. Adv. Mater., 24, 5088 (2012).

[8] A. Fleurence, R. Friedlein, T. Ozaki, H. Kawai, Y. Wang, Y. Takamura. Phys. Rev. Lett., 108, 245501 (2012).

[9] L. Meng, Y. Wang, L. Zhang, S. Du, R. Wu, L. Li, Y. Zhang, G. Li, H. Zhou, W.A. Hofer, M.J. Gao. Nano Lett., 13, 685 (2013).

[10] Y. Ding, Y. Wang. Nanoscale Res. Lett., 10, 13 (2015).

[11] A. Kara, H. Enriquez, A.P. Seitsonen, L.C.L.Y. Voon, S. Vizzini, B. Aufray, H. Oughaddou. Surf. Sci. Reports, 67 (1), 1 (2012).

[12] H. Nakano, Y. Sugiyama, T. Morishita, M.J.S. Spencer, I.K. Snook, Y. Kumai, H. Okamoto. J. Mater. Chem. A, 2, 7588 (2014).

[13] M. De Crescenzi, I. Berbezier, M. Scarselli, P. Castrucci, M. Abbarchi, A. Ronda, F. Jardali, J. Park, H. Vach. ACS Nano, 10 (12), 11163 (2016).

[14] J. Zhao, H. Liu, Z. Yu, R. Quhe, S. Zhou, Y. Wang, C.C. Liu, H. Zhong, N. Han, J. Lu, Y. Yao, K. Wu. Progr. Mater. Sci., 83, 24 (2016).

[15] A.E. Galashev, O.R. Rakhmanova, K.A. Ivanichkina, A.S. Vorob'ev. Phys. Solid State, 59 (6), 1242 (2017).

[16] A.E. Galashev, O.R. Rakhmanova, K.A. Ivanichkina. J. Struct. Chem., 59 (4), 877 (2018).

[17] H.Q. Ho, Y. Honda, M. Motoyama, S. Hamamoto, T. Ishii, E. Ishitsuka. Appl. Radiat Isot., 135, 12 (2018).

[18] M.L. Kozhukh. Nucl. Instrum. Meth. Phys. Res. A, 329, 453 (1993).

[19] I.S. Shlimak. Phys. Solid State, 41 (5), 716 (1999). 
[20] J.M Soler, E. Artacho, J.D. Gale, A. García, J. Junquera, P. Ordejon, D. Sanchez-Portal. J. Physics: Condens. Matter, 14 (11), 2745 (2002).

[21] W. Hu, Z. Li, J. Yang. J. Chem. Phys., 139, 154704 (2013).

[22] S.K. Gupta, H.R. Soni, P.K. Jha. AIP Advances, 3 (3), 032117 (2013).

[23] N. Pantha, A. Khaniya, N.P. Adhikari. Int. J. Mod. Phys. B, 29 (20), 1550143 (2015).

[24] S. Xu, X. Fan, J. Liu, D.J. Singh, Q. Jiang, W. Zheng. Phys. Chem. Chem. Phys., 20, 8887 (2018).

[25] T. Hussain, S. Chakraborty, R. Ahuja, Chem. Phys. Chem., 14 (15), 3463 (2013).

[26] M.A. Bin Hamid, C.K. Tim, Y. Bin Yaakob, M.A. Bin Hazan. Mater. Res. Express, 6 (5) (2019).

[27] R. Zhou, L.C.L.Y. Voon, Y. Zhuang. J. Appl. Phys., 114, $093711(2013)$

[28] J.E. Padilha, R.B. Pontes. J. Phys. Chem. C, 119(7) 3818 (2015).

[29] J. Sivek, H. Sahin, B. Partoens, F.M. Peeters. Phys. Rev. B, 87, 085444 (2013).

[30] T.L. Brown, H.E. LeMay, B.E. Bursten. J. Chem. Education, 74 (4) (1997).

[31] M.S. Silberberg. Chemistry: The Molecular Nature of Matter and Change. 5th Edn (N.Y., The McGraw-Hill Companies, Inc., 2009).

[32] A.Y. Galashev, Yu.P. Zaikov. J. Appl. Electrochem., 49, 1027 (2019).

[33] W. Liu, H. Zhi, X. Yu. Energy Storage Mater., 16, 290 (2019).

[34] A.E. Galashev, Yu.P. Zaikov, R.G. Vladykin. Russian J. Electrochem., 52 (10), 966 (2016).

\section{Electronic properties of silicene films subjected to neutron doping}

\author{
A.E. Galashev ${ }^{1,2}$, A.S. Vorob'ev ${ }^{1}$ \\ ${ }^{1}$ Institute of High Temperature Electrochemistry, \\ Ural Branch of the Russian Academy of Sciences, \\ 620990 Yekaterinburg, Russia \\ 2 Ural Federal University \\ named after the first President of Russia B.N. Yeltsin, \\ 620002 Yekaterinburg, Russia
}

Abstract Radiation doping with phosphorus of single-crystal silicon preserves the structure of the sample, reduces internal stresses, and increases the lifetime of minority charge carriers. This work is devoted to the study of the effect of phosphorus additives on the electronic properties of silicene. Using the quantum-mechanical method, the band structure and the density spectra of electronic states of phosphorus-doped single-layer $4 \times 4$ silicene on a graphite substrate are calculated. The presence of a carbon substrate gives the silicene conductive properties due to $p-p$ hybridization. Doping with phosphorus can preserve or alter the metallic properties acquired by silicene. The location of doping phosphorus atoms in silicene affects the passage of the semiconductor - conductor transition. The theoretical specific capacity of the phosphorus-doped silicene is reduced, and it becomes less effective for use in lithium-ion batteries. However, an increase in the conductivity of this material contributes to its use as solar cells.

Редактор Г.А. Оганесян 